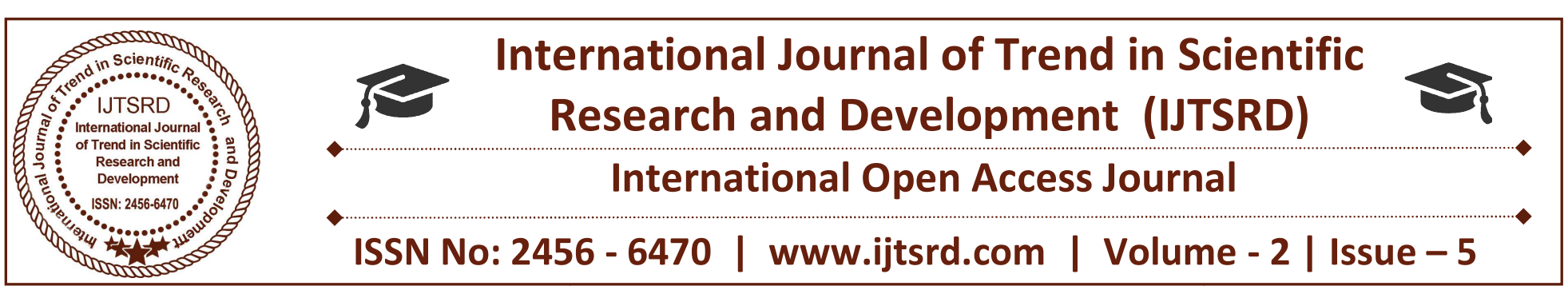

\title{
Role of Thermoplastic Granulus for the Improvement of Strength of Clay Soil
}

\author{
V. Gunasekaran ${ }^{1}$, M. Sandhiya ${ }^{2}$ \\ ${ }^{1}$ Lecturer Senior Grade, ${ }^{2}$ Lecturer \\ Department of Civil Engineering, Nachimuthu Polytechnic College, Pollachi, India
}

\begin{abstract}
Soil stabilization is any process which improves the physical properties of soil, such as increasing shear strength, bearing capacity etc. which can be done by use of controlled compaction or addition of suitable admixtures like cement, lime and waste materials like fly ash, phosphogypsum etc. The cost of introducing these additives has also increased in recent years which opened the door widely for the development of other kinds of soil additives such as plastics, bamboo etc. This new technique of soil stabilization can be effectively used to meet the challenges of society, to reduce the quantities of waste, producing useful material from non-useful waste materials. Using of plastic wastes such as plastic bags, PVC powder from industry and construction and demolition waste is increasing day by day leading to various environmental concerns. Therefore the disposal of the plastic wastes without causing any ecological hazards has become a real challenge. Thus using PVC as a soil stabilizer is an economical utilization since there is scarcity of good quality soil for embankments.
\end{abstract}

This paper describes an experimental study on mixing PVC waste powder with clayey soil at different mixing ratios $(0,0.25,0.50$, and 0.75$) \%$ by weight respectively. For the clay Soil, Shear Strength parameter and Cohesion Value are obtained by conducting Unconfined Compressive Strength (UCC) test and Maximum Dry Density is found by Standard Proctor Test.

Keywords: Soil improvement, plastic waste, PVC powder, shear, compaction.

\subsection{INTRODUCTION}

The amount of plastic wastes has increased year by year and the disposal becomes a serious problem. Particularly, recycling ratio of the plastic wastes in life and industry is low and many of them have been reclaimed for the reason of unsuitable ones for incineration. The disposal of polyvinyl chloride (PVC) plastic threatens public health and the environment. Although problematic throughout its lifecycle - from production through final use - the discarding of PVC as waste poses perpetual hazards. PVC is widely used in plastic pipes, building materials (e.g., vinyl siding, windows), consumer products, disposable packaging and many everyday products. Land disposal of PVC is also problematic. Dumping PVC in landfills poses significant long-term environmental threats due to leaching of toxic additives into groundwater, dioxin-forming landfill fires, and the release of toxic emissions in landfill gases. Most PVC in construction and demolition debris ends up in landfills, many of which are unlined and cannot capture any contaminants that leak out. We can prevent harm from PVC by replacing it with safer, cost-effective alternatives that are available, and by diverting PVC waste away from incineration and Open burning. It is necessary to utilize the wastes effectively with technical development in each field. Our project presents the use of plastic waste (PVC powder) in the field of civil engineering as reinforcing material. Reinforced soil construction is an efficient and reliable technique for improving the strength and stability of soils. The technique is used in a variety of applications, ranging from retaining structures and embankments to subgrade stabilization beneath footings and pavements. 
Our project describes an experimental study on mixing PVC waste in form of powder with clayey soil at different mixing ratios $(0,0.25,0.50$, and 0.75$)$ \%by weight respectively. The shear strength parameters of reinforced and unreinforced samples were investigated by the Unconfined Compression Test (UCC Test). In addition, a series of compaction tests were performed on clayey soil mixed with different percentages of plastic granules. It was found that, there is significant improvement in the strength of soils due to increase in internal friction. Also, it was concluded that the plastic pieces decreases the maximum dry density of the soil due to their low specific gravity and decreases the optimum moisture content.

\subsection{Plastic Waste as Soil Reinforcement}

Plastic waste when mixed with soil behaves like a fiber reinforced soil. Plastic wastes are distributed throughout a soil mass; they impart strength isotropy and reduce the chance of developing potential planes of weakness. Hence uses of plastic waste for improving the engineering properties of soil are taken up in the present study. Mixing of plastic waste with soil can be carried out in a concrete mixing plant of the drum mixer type (Lindh 1990) or with a selfpropelled rotary mixer (Santoni and Webster 2001). Plastic waste could be introduced either in specific layers or mixed randomly throughout the soil. An earth mass stabilized with discrete, randomly distributed plastic waste resembles earth reinforced with chemical compounds such as lime, cement etc. in its engineering properties.

\subsection{Advantages of Soil Reinforced With PVC Waste}

The following are the specific advantages of soil mixed with plastic waste.

$>$ Improves strength, stiffness, ductility and toughness of soil.

$>$ Maintains strength isotropy which resists shear band formation.

$>$ Improves the piping resistance of soil.

$>$ Increases resistance against liquefaction under dynamic loading conditions.

$>$ Reduces compressibility of soil.

\subsection{Index Properties of soil}

Specific Gravity of Soil is 2.655

Organic content of the soil is $6.6 \%$

Liquid Limit of the soil sample is $51.7 \mathrm{ml}$

\subsection{Wet Sieve Analysis}

A representative soil sample of about $1 \mathrm{~kg}$ is taken, using riffler, and dried in an oven. The dried sample is taken in a tray and soaked with water. If deflocculation is required, sodium hexametaphosphate, at the rate of $2 \mathrm{~g}$ per liter of water is added. The sample through a $4.75 \mathrm{~mm}$ and washed with a jet of water. The material retained on the sieve is the gravel fraction. It is dried in an oven and sieved through set of coarse sieves.

The material passing through $4.75 \mathrm{~mm}$ sieve is sieved through a $75 \mu$ sieve. The material is washed until the wash water becomes clear. The material retained on the $75 \mu$ sieve is collected and dried in an oven .It is then sieved through the set of fine sieves of the size $2 \mathrm{~mm}, 1 \mathrm{~mm}, 600 \mu, 425 \mu, 212 \mu, 150 \mu$, and $75 \mu$. The material retained on each sieve is collected and weighed. The material that would have been retained on pan is equal to the total mass of the soil minus the sum of the masses of material retained on all sieves.

\section{Observation \& Result:}

D Amount of sample taken $=1 \mathrm{~kg}$

$>$ Weight retained on $75 \mu=0.269 \mathrm{~kg}$ About $73 \%$ of sample passed through $75 \mu$ sieve so the soil sample is Fine Grained Soil

Grain size distribution is done for retained soil sample.

\section{Engineering Properties \\ 3.1.3 Apparatus}

\subsubsection{Moulds}

It shall conform to IS: $10074-1982 \S$.

\subsubsection{Sample Extruder (Optional)}

It consists of a jack, lever frame or other device adopted for the purpose of extruding compacted specimens from the mold.

\subsubsection{Balances}

One, of capacity $10 \mathrm{~kg}$ sensitive to $1 \mathrm{~g}$ and other of capacity $200 \mathrm{~g}$ sensitive to $0.01 \mathrm{~g}$.

\subsubsection{Oven}

Thermostatically controlled with interior of noncorroding material to maintain temperature between $105^{\circ} \mathrm{C}$ and $110^{\circ} \mathrm{C}$. 


\subsubsection{Container}

Any suitable non-corrodible airtight container to determine the water content for tests conducted in the laboratory.

\subsubsection{Steel Straightedge}

A steel straightedge about $30 \mathrm{~cm}$ in length and having one beveled edge.

\subsubsection{Sieve}

$4.75-\mathrm{mm}$ and $19-\mathrm{mm}$ IS sieves conforming to the requirements of IS: 460 (Part I)-1978*.

\subsubsection{Mixing Tools}

Miscellaneous tools, such as tray or pan, spoon, trowel and spatula, or a suitable mechanical device for thoroughly mixing the sample of soil with additions of water.

\subsubsection{Metal Rammer}

It shall conform to IS: $9198-1979 \dagger$.

\subsubsection{Procedure}

Soil sample sieve by $4.75 \mathrm{~mm}$ sieve from that $2.5 \mathrm{~kg}$ sample had taken. Initially empty weight of mold had taken with the help of weight balancing. Then initially $4 \%$ of water content had been added to soil sample. Then soil sample had placed in the tray, in that soil sample had been mixed in even. Then sample divided into 3 layers with equal mass. The first layer of soil sample had placed in the mold. For each layer we should give 25 blows. The blows shall be distributed uniformly over the surface of each layer. Then upper caller had removed from mold. The extension had been removed and the compacted soil had been leveled off carefully to the top of the mold by means of the straightedge. The mould and soil had been weighed. Then next the same percentage of water content had added to soil sample. The same procedure had been continuing until soil and mold weight decrease. The observation reading had been noted in the table. From the table we can take water content, bulk density, dry density, zero air voids. For these reading we plot a graph from that graph we take optimum moisture content. From maximum dry density draw a straight line to water Content that water content is optimum moisture content for the soil sample.

For PVC powder added sample also had these procedures. But there is only one change before adding water content we should add PVC powder to the soil sample. Then mix it even and then water content should add. For different type of PVC powder added soil sample had tested. PVC powder added percentage is $0.25 \%, 0.50 \%, 0.75 \%$.

\begin{tabular}{|c|c|c|c|c|c|c|c|c|c|c|c|c|}
\hline & \multicolumn{3}{|c|}{ Normal Clay } & \multicolumn{3}{c|}{$0.25 \%$ of PVC } & \multicolumn{3}{c|}{$0.50 \%$ of PVC } & \multicolumn{3}{c|}{$0.75 \%$ of PVC } \\
\hline $\begin{array}{c}\text { Water Content } \\
\%\end{array}$ & 4 & 16 & 28 & 12 & 18 & 22 & 4 & 16 & 24 & 4 & 16 & 20 \\
\hline $\begin{array}{c}\text { Mass Mold + } \\
\text { Compacted Soil } \\
(\mathrm{M} 1, \mathrm{~g})\end{array}$ & 6.158 & 6.249 & 6.642 & 6.457 & 6.589 & 6.649 & 6.056 & 6.393 & 6.415 & 6.108 & 6.320 & 6.227 \\
\hline $\begin{array}{c}\text { Mass of } \\
\text { Compact soil } \\
(\mathrm{M}, \mathrm{g})\end{array}$ & 1.512 & 1.603 & 1.996 & 1.811 & 1.943 & 2.003 & 1.41 & 1.747 & 1.769 & 1.462 & 1.674 & 1.581 \\
\hline $\begin{array}{c}\text { Bulk Density } \\
\left(\mathrm{g} / \mathrm{cm}^{3}\right)\end{array}$ & 1.540 & 1.633 & 2.033 & 1.846 & 1.98 & 2.041 & 1.437 & 1.781 & 1.803 & 1.489 & 1.705 & 1.610 \\
\hline $\begin{array}{c}\text { Dry Density } \\
\left(\mathrm{g} / \mathrm{cm}^{3}\right)\end{array}$ & 1.480 & 1.53 & 1.523 & 1.648 & 1.678 & 1.673 & 1.382 & 1.535 & 1.454 & 1.390 & 1.580 & 1.346 \\
\hline $\begin{array}{c}\text { Zero Air Density } \\
\left(\mathrm{g} / \mathrm{cm}^{3}\right)\end{array}$ & 2.396 & 2.011 & 1.521 & 2.011 & 1.794 & 1.674 & 2.396 & 1.861 & 1.620 & 2.396 & 1.861 & 1.732 \\
\hline
\end{tabular}

Table 1: Combined properties of Normal Clay and Clay $+(0.25,0.50,0.75) \%$ of PVC added Soil 


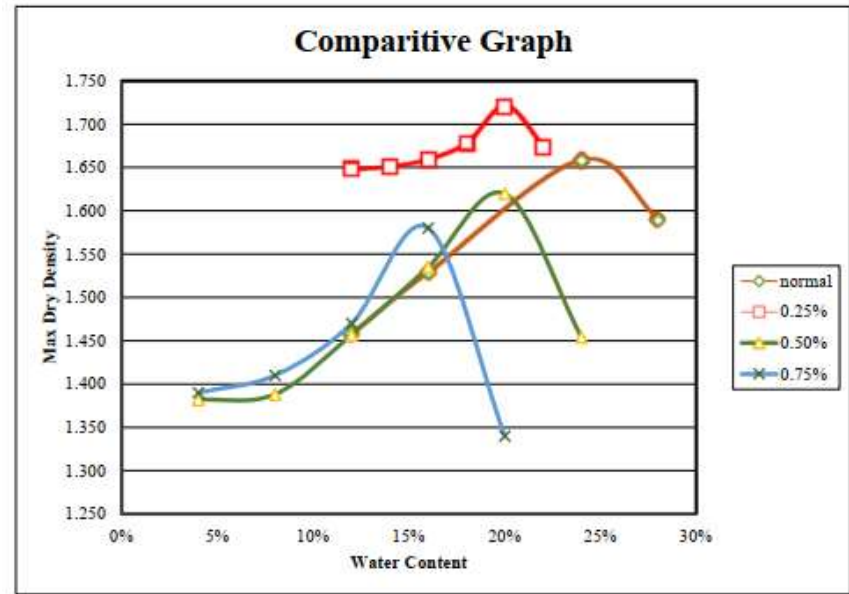

Figure 1: Comparative Graph of Soil Properties

\subsection{Unconfined Compressive Strength}

\subsubsection{Apparatus}

\subsubsection{Compression Device}

The compression device may be any of the following types:

A. Platform weighing scale equipped with a screw-jack activated yoke;

B. Hydraulic loading device;

C. Screw jack with a proving ring; and

D. Any other loading device.

Al1 these loading devices shall have sufficient capacity and strain control.

\subsubsection{Proving Ring}

The selection of the proving ring shall depend on the following:

For relatively weak soil with qu less than $100 \mathrm{KPa}$ (1 $\mathrm{kgf} / \mathrm{cms}$ ) load shall be measurable to $1 \mathrm{KPa}$. For soils with qu equal to or greater than $100 \mathrm{KPa}(1 \mathrm{kgf} / \mathrm{cms})$ load shall be measurable to the nearest $5 \mathrm{KPa}$ $(0.05 \mathrm{kgf} / \mathrm{cms})$. The calibration of the proving ring shall be checked frequently, at least once a year.

\subsubsection{Deformation Dial Gauge}

Axial deformation of the sample shall be measured with a dial gauge having a least count of $0.01 \mathrm{~mm}$ and travel to permit not less than 20 percent axial strain.

\subsubsection{Vernier Calipers}

Suitable to measure physical dimensions of the test specimen to the nearest $\mathrm{O}-1 \mathrm{~mm}$.

\subsubsection{Timer}

Timing device to indicate the elapsed testing time to the nearest second may be used for establishing the rate of strain.

\subsubsection{Oven}

Thermostatically controlled, with interior of noncorroding material capable of maintaining the temperature at $110^{\circ} \mathrm{C} \mathrm{f} 5^{\circ} \mathrm{C}$.

\subsubsection{Weighing Balances}

Suitable for weighing soil specimens specially. Specimens of less than $100 \mathrm{~g}$ shall be weighed to the nearest $0.01 \mathrm{~g}$ whereas specimens of $100 \mathrm{~g}$ or larger shall be weighed to the nearest $0.1 \mathrm{~g}$.

\subsubsection{Miscellaneous Equipment}

Specimen trimming and carving tools, remolding apparatus, water content cans, data sheets, etc, as required.

\subsubsection{Procedure}

The initial length, diameter and weight of the specimen had been measured and the specimen placed on the bottom plate of the loading device. The upper plate had been adjusted to make contact with the specimen. The deformation dial gauge had been adjusted to a suitable reading, preferably in multiples of 100 . Force had been applied so as to produce axial strain at a rate of 0.5 to 2 percent per minute causing failure with 5 to 10 . The force reading had been taken at suitable intervals of the deformation dial reading. The specimen had been compressed until failure surfaces have definitely developed, or the stress-strain curve is well past its peak, or until an axial strain of 20 percent is reached. The failure pattern had been sketched care full and shown on the data sheet or on the sheet presenting the stress-strain plot. The angle between the failure surface and the horizontal may be measured, if possible, and reported. The water content of the specimen had been determined in accordance with IS 2720 (Part2): 1973 using samples taken from the failure zone of the specimen. The above procedure had been same for while PVC powder added and then determining the unconfined compressive strength. 


\begin{tabular}{|c|c|c|c|c|c|c|c|c|c|c|c|c|}
\hline Observation & \multicolumn{3}{|c|}{ Normal Clay } & \multicolumn{3}{|c|}{$0.25 \%$ of PVC } & \multicolumn{3}{c|}{$0.50 \%$ of PVC } & \multicolumn{3}{c|}{$0.75 \%$ of PVC } \\
\hline Load, N & 85 & 165 & 235 & 205 & 285 & 323 & 115 & 215 & 265 & 65 & 187.5 & 257.5 \\
\hline $\begin{array}{c}\text { Cross } \\
\text { Sectional Area, } \\
\text { cm }^{2}\end{array}$ & 11.44 & 12.24 & 12.80 & 11.44 & 11.92 & 12.80 & 11.53 & 12.03 & 12.57 & 11.4 & 81.58 & 5.68 \\
\hline Strain & 0.008 & 0.073 & 0.113 & 81.58 & 485.53 & 1132 & 161.84 & 567.1 & 971 & 11.8 & 405.2 & 15.86 \\
\hline Stress, N/cm & 7.43 & 13.48 & 18.37 & 17.92 & 2.90 & 2.520 & 9.97 & 17.88 & 21.09 & 12.6 & 971 & 20.49 \\
\hline
\end{tabular}

Table 2: Unconfined Compressive Strength of Clay and Clay + PVC

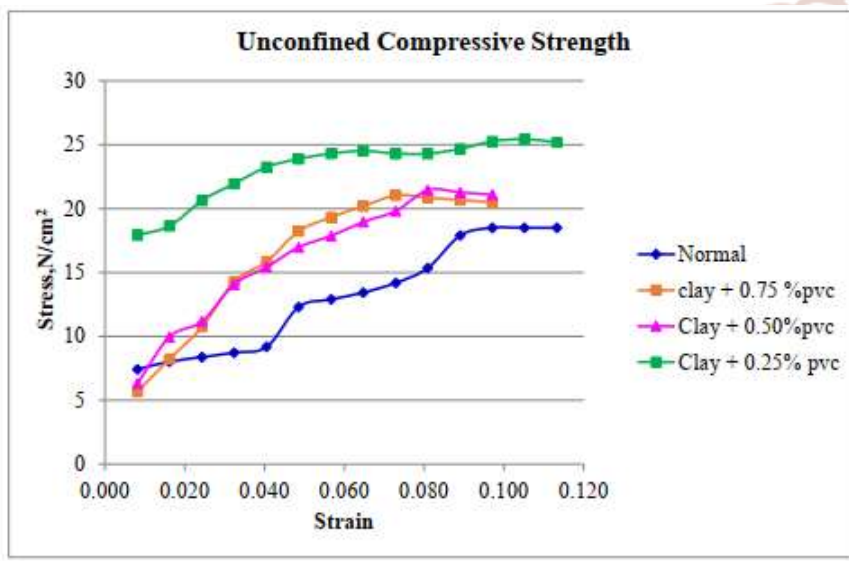

Figure 2: Comparative Graph of Unconfined Compressive Strength

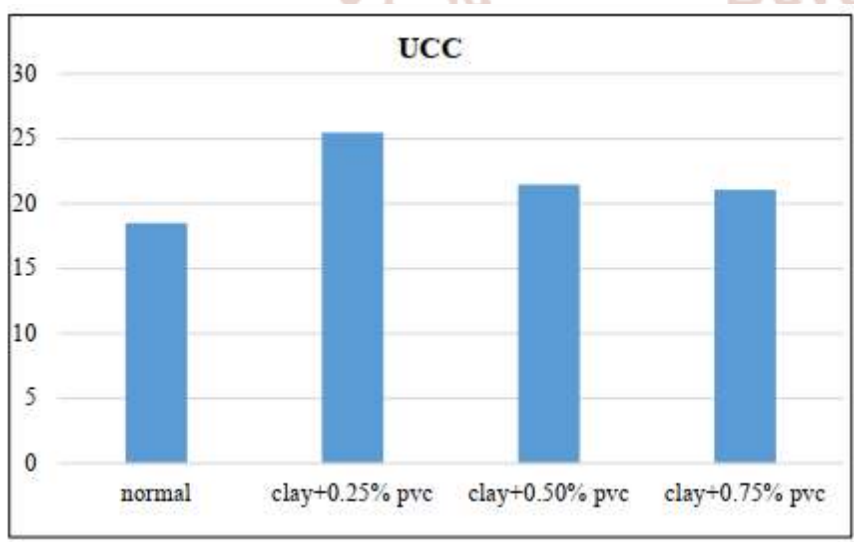

Figure 3: Interpretation from Results

\section{Results}

\begin{tabular}{|c|c|}
\hline Properties of Soil & Index Value \\
\hline Specific Gravity & 2.655 \\
\hline Liquid limit & 51.7 \\
\hline Organic Content & 6.6 \\
\hline
\end{tabular}

Table 3: Index Property Results

\begin{tabular}{|c|c|c|c|}
\hline Sample & OMC & $\begin{array}{c}\text { Dry Density } \\
\mathrm{g} / \mathrm{cm}^{3}\end{array}$ & $\begin{array}{c}\text { Shear } \\
\text { Strength } \\
\text { N/sq.cm }\end{array}$ \\
\hline 0 & 24 & 1.67 & 18.14 \\
\hline 0.25 & 22 & 1.72 & 25.44 \\
\hline 0.50 & 20 & 1.62 & 21.47 \\
\hline 0.75 & 16 & 1.58 & 21.04 \\
\hline
\end{tabular}

Table 4: Comparative Analysis of Engineering Properties

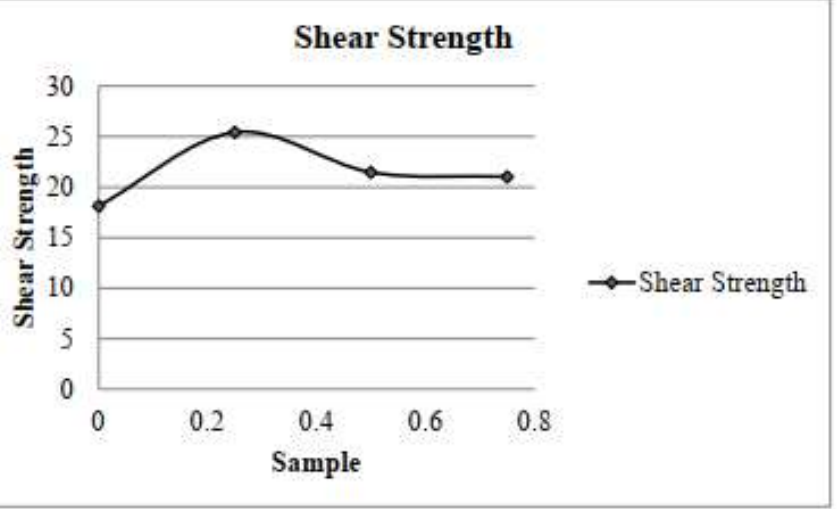

Figure 4: Shear Strength of Samples

\section{Conclusion}

The water absorption of PVC mixed soil decreases with increase in percentage of PVC powder because it is an inert material.

By adding $0.25 \%$ of PVC powder, the dry density increases but further addition the dry density decreases. Since, up to addition $0.25 \%$ of PVC powder is sufficient to fill the voids. So, further addition of PVC powder does not show any increase of dry density value. 


\section{References}

1. Ling, H.I.; Leshchinsky, D.; and Tatsuoka, F. (2003). Reinforced Soil Engineering: Advances in Research and Practice. Marcel Dekker Incorporated, New York, 33.

2. Bowles, J.E. (1992). Engineering properties of soils and their measurement (4th Ed.). London: McGraw- Hill Int., 78-89.

3. Ingles, O.G.; and Metcalf, J.B. (1992). Soil stabilisation principles and practice. Boston: Butterworth Publishers.

4. Al-Khafaji, A.W.; and Andersland, O.B. (1992). Geotechnical engineering and soil testing. New York: Sounder College Publishing.

5. Al-Joulani, N. (2000). Engineering properties of slurry waste from stone cutting industry in the west bank. Proceedings of the First Palestine Environmental Symposium, PPU, Hebron.

6. Gray, D.H. (2003). Optimizing soil compaction and other strategies. Erosion Control, 9(6), 34-41.

7. Consoli, N.C.; Prietto, P.D.M.; and Ulbrich, L.A. (1998). Influence of fiber and cement addition on behaviour of sandy soil. Journal of Geotechnical and Geoenvironmental Engineering, ASCE, 124(12), 1211-1214.

8. Consoli, N.C.; Montardo, J.P.; Prietto, P.D.M.; and Pasa, G.S. (2002). Engineering behaviour of sand reinforced with plastic waste. Journal of Geotechnical and Geoenvironmental Engineering, ASCE, 128(6), 462-472.

9. Gray, D.H.; and Lin, Y.K. (1972). Engineering properties of compacted fly ash. Journal of Soil Mechanics and Foundations Divisions, ASCE, 98(4), 361-380.

10. Fletcher, C.S.; and Humphires, W.K. (1991). California bearing ratio improvement of remoulded soil by the addition of polypropylene fiber re inforcement. Transport Research Record, No. 1295, TRB, Washington D.C., 80-86. 